Mr. Bland Sutton, assisted by myself, chloroform being administered by Mr. Owen Coker, made an incision from the margin of the ribs on the right side clown in a line with the onter border of the rectus muscle, about 3 in. in length, and the peritoneum was incised. There was no enlargement of the gall-bladder but a small stone could be felt in it. 'The gall-bladder was opened and this was removed. It was quite loose in the viscus. Behind the gall-bladder, underneath the liver could be felt indistinctly a large resisting body in the situation of the common bile duct. 'The abdominal' wound was enlarged, the liver was pulled up as high as possible, and the pylorus was pulled aside. After cautiously working down with the finger $\mathrm{Mr}$. Bland Sutton came on the greatly distended common bile duct, and in this, just past the opening of the cystic duct, was felt a large stone. Strong efforts were made to push it back into the gall-bladder or onwards into the bowel, but, owing to its size, without avail. An incision about $1 \frac{1}{2}$ in. long was made in the long diameter of the duct and the stone was easily expressed. It was composed of cholesterin, was $2 \mathrm{in}$. long and $3 \frac{1}{2}$ in round, was quite smooth, ovoid in form, and weighed 7 drachms. There was but slight bleeding. The incision in the duct was not sutured. A large indiarubber drainage-tube was put in down to the bottom of the abdominal wound, the gall-bladder was closed and stitched to the parietes, and the abdominal walls were closed by three layers of sutures-fine silk for the peritoneum, silkworm gut for the muscles and fascia, and silk for the skin and subcutaneous tissues. It was dressed with the usual antiseptic dressing. After the operation the patient suffered a good deal of pain, which was relieved by small hypodermic injections of morphia for the first twentyfour hours. The temperature never rose above $100^{\circ} \mathrm{F}$. and the pulse kept good. There was for the first three days a profuse discharge of bile, at least 2 or 3 pints daily, requiring frequent dressing of the wound. The tube was gradually shortened and it was removed altogether in about seven days. There was no discharge of bile after the third day. The abdominal wound closed by first intention and the patient made an uninterrupted recovery, with the exception that several of the buried silkworm gut sutures caused small abscesses and were gradually in the course of some months brought to the surface and removed quite undissolved. Since the operation he has never had another attack of biliary colic. He has gained $3 \frac{1}{2}$ st. in weight and can eat any ordinary food with impunity. The scar is firm and strong and there is no ventral hernia.

Acton, W.

\section{A CASE OF PY \&MIA TREATED WITH INJECTIONS OF ANTI-STREPTOCOCCIC SERUM.}

BY HERBERT M. RAMSAY, F.R.C.S. EDIN.

A GIRT, aged fourteen years, developed measles on Feb. 27th, 1898. She went on well, it appeared, until March $3 r d$, when, at about 4 A.M., she complained of pain in the right ear. The pain continued to get worse, the child throwing herself about in bed all through the day and night of the 3rd. On the morning of the $4 \mathrm{th}$ the pain got better and the nurse noticed some discharge from the ear. In the evening the temperature was $104^{\circ} \mathrm{F}$. and the patient complained of pain behind the ear. I saw her for the first time on the evening of the 5 th, when her temperature was $105^{\circ}$. She had had a "shivering fit." Her pulse was 120 , the respirations were 24 , and she was very restless. There was some pain behind the right ear, but this was not increased by pressure and there was no redness or swelling there. On examining the ear I found the meatus filled with inspissated pus and débris and on clearing this out the membrane was seen to be white and sodden and there was a perforation situated at the anterior and inferior part of the membrane. After this her temperature fell to $103^{\circ}$ and she had some sleep. The ear was ordered to be kept syringed out with a perchloride of mercury lotion ( 1 in 4000) and a 2-gr. pill of quinine was directed to be given every six hours. When I saw her again on the evening of the 6th the patient's temperature had gone up to $104^{\circ}$ again, her pulse was 120 , and the respirations were 26 . I found that the meatus was again blocked with pus and after cleaning this out her temperature fell during the night to $99^{\circ}$ and there was a profuse discharge from the ear. In spite of her ear being kept well syringed her temperature rose on the evening of the 7 th to $106^{\circ}$. Her pulse was then 130 , the respirations were 30 , and some dulness was detected at the base of both lungs. She still complained of pain behind the ear and the tip of the mastoid was very tender on pressure. On the 8 th her temperature kept at about $103^{\circ}$ and there was free discharge from the ear. She was restless and sick several times after food, but there was no delirium. The quinine was increased to 2 grs. every four hours and she was given a drachm of brandy with each quinine pill. Mr. Bowlby saw the patient with me on the evening of the 8th, and we decicled that there was no immediate indication for opening the mastoid cells. Her temperature was then $105.4^{\circ}$. She complained of pain at the tip of the mastoirl, and this spot was tender on pressure, but there was no pain or tenderness over the mastoid cells and no headache. She was restless but she had no cerebral symptoms and there was no tenderness over the course of the jugular vein. She had been sick several times after her food and she had had a slight rigor. She slept fairly well and was better on the 9 th, but there were patches of dulness all over both lungs, with fine crepitation and tubular breathing. She had a slight cough but very little expectoration. Her temperature in the evening was $104.6^{\circ}$, her pulse was 104 , and the respirations were 32 . On the morning of the 10th her temperature was $99^{\circ}$ but it rose again in the afternoon to $104 \cdot 4^{\circ}$, when Mr. Bowlby again saw her with me. The patient was now very ill and it was decided to open the mastoid cells, which was done at 4.30 P.M. when Mr. Willett administered the chloroform. Mr. Bowlby onened the mastoid cells and found nothing there except some muco-purulent secretion, but not sufficient of this to account for the high temperature, so no attempt was macle to open up the tympanum. The skull was then opened but the dura mater did not bulge and the lateral sinus was evidently not occluded and the wound was therefore closed. The patient took chloroform well and she went to sleep after $\frac{1}{6} \mathrm{gr}$. of morphia had been injected subcutaneously. Her temperature rose to $105^{\circ}$ in the evening, but on the morning of the 11 th it fell to $99.4^{\circ}$ and she seemed to be much better. In the afternoon, however, she had a slight rigor and her temperature rose once more to $105^{\circ}$. The respirations were 38 . On the 12 th she was troubled a good deal by cough and had some purulent expectoration. Her temperature in the morning was $96.4^{\circ}$ and in the evening it was $104.4^{\circ}$. She had well-marked pneumonia in patches over both lungs. Her condition on the 13th and 14th was much the same. The patient was troubled by cough and she was restless and took her nourishment badly. On the night of the 14th she slept very little and complained of pain in her right wrist and hand. The temperature on the morning of the 15th. was $101 \cdot 4^{\circ}$. The right wrist being swollen and very painful it was dressed with belladonna and glycerine and put up on a light cardboard splint. The wound behing the ear was almost healed. She had a rigor in the afternoon and her temperature went up to $104^{\circ}$. On the 16 th and 17 th the patient was very ill. She had frequent rigors and her temperature ranged from $96^{\circ}$ to $105^{\circ}$. She was very sick and restless. On the 18 th the morning temperature was $96^{\circ}$, the pulse was 120 and very weak and the respirations were 32. She was constantly sick and took no notice of anything. Dr. Herringham saw the patient with me at 6 P.M. on the 18th. Her temperature was then $104^{\circ}$ and though the lungs were clearing up she still seemed very ill. It was decided to try injection of anti-streptococcic serum and Dr. Herringham accordingly injected 5 c.c. into the loin. For a short time she complained of pain at the site of the injection, but this soon passed off and she slept well and more naturally. The blood was examined and was found to contain numerous streptococci and a few staphylococci. There were streptococci in the sputum but no organisms were found in the discharges from the ear. On the 19th the patient had three injections of 10 c.c. each of serum at 8.30 A.M., 1 P.M., and 6.30 P.M. She seemed to have improved and she took her nourishment better. The urine was examined; it contained no albumin. On the 20th and 21st she had three injections each day, at 8.30 A.M. and 1.30 and 6.30 P.M. She was now decidedly better, but though she had no rigors her temperature remained high in the evening, though it was lower than it had been. The lungs were clearing up well 
and she slept better. She was not sick and she took her nourishment more freely. There was no trace of albumin in the urine. On the 22nd her temperature in the morning was $98.6^{\circ}$ and in the evening $102.5^{\circ}$. The pulse was 100 and the respirations were 26 . As she was so much better and as, being a very nervous child, the thought of the injections distressed her so much, it was clecicled to discontinue them. The specific gravity of the urine was 1020 ancl there was a trace of albumin. On the 23rd she was much brighter and better and she took her nourishment well, though her temperature in the morning was $95^{\circ}$ and in the evening $101.8^{\circ}$. The wrist was much better and she was able to leave off the splint. On the 24th the patient was not so well and her temperature was $102.4^{\circ}$ in the evening. The urine contained no trace of albumin. She was giren an injection of 10 c.c. of serum at 6.30 P.M. On the 25th she had three injections of 10 c.c. each and she again seemed better. Her temperature was still very low in the mornings and high in the evenings $\left(104^{\circ}\right)$, but ther general condition was much improved. She complained of pain in the left buttock, where there was some fulness but mo definite lesion could be made out. Belladonna and olycerine and hot fomentations were applied. On the 26th, 27 th, and 28th she had one injection each day of 10 c.c. and she seemed to be steadily improving, though her temperature ranged from $104^{\circ}$ to $95^{\circ}$. On the 29 th she was not so well, her temperature was $102 \cdot 4^{\circ}$, and two injections each of 10 c.c. were given at $8.30 \mathrm{~A} . \mathrm{M}$. and $6.30 \mathrm{P.M}$. On the 30 th she was better, but she still complained of pain in the left buttock. She was given an injection of 10 c.c. at 8.30 A.M. and this was the last administered as the blood on examination showed no micrococci. Her temperature still varied from $95^{\circ}$ to $104^{\circ}$ but she ate and slept well. The chest was quite clear and the pulse was good and steady. On April 3rd and 4th she complained a good deal of pain in the left buttock and was quite unable to lie on that side. There was fulness, and as the skin was so tender that it was quite impossible to examine the place it was decicled to put her under an anæsthetic for that purpose and this was done on the 7th. Fluctuation being detected Mr. Bowlby cut down and opened a large abscess situated beneath the glutei and evacuated about $10 \mathrm{oz}$. of pus. A counter opening was made and a large drainage-tube put in. Her temperature rose to $105^{\circ}$ in the evening but she slept fairly well. On the 8th the patient was very sick all day and also on the 9 th, on the evening of which day her temperature rose to $105.6^{\circ}$, her pulse was small (130) and running, and her respiration was shallow. She was very restless and delirious. The abscess was dressed but there was apparently no retention of pus and nothing to account for her condition. Morphia ( $\frac{1}{6}$ gr.) was administered subcutaneously, and after this she became quiet and slept for the greater part of the night. On the 10th she was much better, the sickness being less. There was little discharge and the wounds looked healthy. The temperature in the evening was 103.8 and she slept well. On the 11th her temperature did not rise above $100^{\circ}$ and she was much better. but she had oedema of the right eyelid and the right side of her forehead. She took her nourishment well and with an appetite. From this time the patient continued to improve; the odema of the eyelid disappeared and she was well enough to go to the country on April 23rd with the wounds almost healed. The drainage-tube was taken out on April 14th as there was no discharge. The patient was last seen on June 5th, when she had quite regained her strength and the hearing of the left ear was much improved. The perforation was healing, the site of the abscess in the buttock was quite sound, and the wrist was quite well.

The interest in this case lies in the great improvement manifested in the patient's condition after the serum treatment was commenced. The temperature did not fall though the average altogether was lower than before the injection but the continued high temperature was accounted for by the presence of the abscess in the buttock. When this was evacuated the temperature almost immediately fell to normal. In spite of the temperature being high the patient's general condition improved markedly. From the time the injections were commenced she slept better, took her nourishment better, and was altogether more natural. The wrist cleared up, her pulse improved, and she was brighter and better, whereas before she seemed in an almost hopeless state. This improvement was, I think, shown to be due to the anti-streptococcic serum treatment, as when for two days the injections were discontinued (from $8.30 \mathrm{~A} . \mathrm{M}$. on
March 22nd till 6.30 P.M. on March 24th) she was manifestly not so well, and she improverl again with the recommencement of the injections. Another point of interest is the complete disappearance of the organisms from the blood within twelve days of the commencement of the treatment. It is also interesting to note that streptococci were demonstrated in the blood and anti-streptococcic serum was used, as I think some cases of failure when anti-streptococcic serum has been tried may have been due to the organisms not having been streptococci. Altogether 205 c.c. of serum were injected by Dr. Herringham, to whom and to Mr. Bowlby my best thanks are due.

Hertford-street, $\mathrm{w}$.

\section{Clinital athotes:}

MEDICAL, SURGICAL, OBSTETRICAL, AND THERAPEUTICAL.

\section{SUDDEN AND COMPLETE INTERSION OF THE}

UTERUS AND CERVIX AFTER THE MENOPAUSE;

VERY SMALL FIBROID NODLLE IN THE FUNDUS ; GANGRENE; OPERATION ; RECOVERY.

Br JAMES Oliver, M.D., F.R.S. EdiN., F.L.S., PHYSICLAN TO THE HOSPITAL FOR WONEY, SOHO-SQUARE.

THE patient was a widow, aged fifty-eight years, who had had six children and three miscarriages. The last child was born twenty years ago and the miscarriages occurred prior to that time. The menstrual discharge, which had always been rather profuse, ceased twelve months ago. During the last three months the patient had observed a slight and constant hæmorrhagic discharge from the vagina and had experienced occasionally "a feeling as though something were coming down in the front passage." Fourteen days ago there suddenly protruded from the external genitals a lump. The presence of this lump had been associated more with a feeling of discomfort than of pain and with the support afforded by a diaper the patient had performed her household duties as usual. Since the lump appeared the discharge had greatly increased and had become purulent and during the last four days it bad been extremely offensive. There had been no bladder symptoms, neither had there been any disturbance of the rectum. There protruded from the external genitals a very sloughy mass which emitted an offensive odour and was composed of three lobes. The lower lobe, which was of the size of a walnut, was solid, the middle one, which measured roughly 3 in. vertically, had a somewhat cystic feel, whilst the upper one, which measured vertically about $2 \mathrm{in}$., had a membranous feel. Immediately above the upper limit of the mass the vaginal mucous membrane displayed anteriorly a dusky red line of demarcation, which extended a little way laterally but was absent altogether posteriorly. In the right lower half of the middle lobe, about an inch above the base of the lower lobe and slightly anteriorly, a small depression was discovered, into which a probe was passed for nearly an inch. As, however, it cansed free hæmorrhage no attempt was made to pass it further, but it was evident that this was the uterine opening of the right Fallopian tube. The mere manipulation of the tumour caused free oozing of blood from the depression between the middle and upper lobes. Posteriorly this depression, which marked the level of the internal os uteri, was almost obliterated. The bladder sound passed straight up towards the pelvis and could not be made to descend towards the raginal mass; the bladder retained, therefore, its normal position. The body temperature nas $101^{\circ} \mathrm{F}$. and the pulse numbered 90 per minute, but the patient otherwise appeared to be in good health.

The tumour and vagina were thoroughly washed with suds made from sapo mollis and afterwards douched well with carbolic lotion. The mucous membrane of the vagina was incised transversely immediately abore the dusky red line of demarcation, and this incision was extended in depth until the peritoneum was reached. The peritoneal cavity was then opened anteriorly but sufficiently only in the first instance to allow of the introduction of the left forefinger. To prevent retraction of the peritoneum a fine 